\title{
LOGÍSTICA REVERSA E LEIS AMBIENTAIS NO BRASIL
}

João Augusto Rodrigues ${ }^{1}$ Universidade da Amazônia jar.finconsul@gmail.com

Norbert Fenzl ${ }^{2}$

Universidade Federal do Pará nfenzl01@gmail.com

\section{Maria do Socorro Almeida Flores ${ }^{3}$ \\ Universidade Federal do Pará saflores@ufpa.br}

\author{
Márcio Teixeira Bittencourt ${ }^{4}$ \\ Universidade Federal do Pará \\ marciobitten@gmail.com
}

Rodolpho Zahluth Bastos 5

Universidade Federal do Pará rodolpho.bastos@gmail.com

\begin{abstract}
Resumo
Este artigo tem como objetivo demonstrar a relação entre as normas e leis ambientais e a reutilização de resíduos e tecnologias de logística reversa no Brasil. Uma revisão pelo método histórico-jurídico das leis, regulamentos e pontos de vista brasileiros em gestão ambiental através das políticas ambientais, mostra as melhorias e perspectivas de tecnologias avançadas de reciclagem e logística reversa, permitindo que as empresas aprimorem suas capacidades de reciclagem e melhorem sua imagem ambiental. Pode-se inferir que a logística reversa pode ser implementada por vários meios, mas requer basicamente regulamentos emitidos por órgãos do poder executivo. Conclui-se que essa é uma vantagem que deve ser aproveitada pelo setor empresarial, a fim de unir forças e oportunidades para lidar com a crescente quantidade enorme de resíduos e os impactos ambientais resultantes, ao mesmo tempo em que obtém resultados sociais e econômicos positivos dos investimentos.
\end{abstract}

Palavras-chave: Brasil. Logística reversa. Leis ambientais.

\footnotetext{
${ }^{1}$ Economista, mestre em Gestão dos Recursos Naturais e Desenvolvimento Local na Amazônia pelo PPGEDAM do Núcleo de Meio Ambiente (NUMA) da Universidade Federal do Pará (UFPA) e doutorado em Administração pelo Programa de Pós-graduação em Administração da Universidade da Amazônia (UNAMA).

2 Geólogo, Doutor em Geologia, Professor do Programa de Pós-graduação em Gestão dos Recursos Naturais e Desenvolvimento Local na Amazônia (PPGEDAM) do Núcleo de Meio Ambiente (NUMA) da Universidade Federal do Pará (UFPA).

3 Bacharel em Direito, Doutora em Desenvolvimento Socioambiental, Professora do Programa de Pós-graduação em Gestão dos Recursos Naturais e Desenvolvimento Local na Amazônia (PPGEDAM) do Núcleo de Meio Ambiente (NUMA) da Universidade Federal do Pará (UFPA).

4 Juiz de Direito, mestre e doutorando do Programa de Pós-graduação em Gestão dos Recursos Naturais e Desenvolvimento Local na Amazônia do Núcleo de Meio Ambiente (NUMA) da Universidade Federal do Pará (UFPA).

5 Bacharel em Direito, Doutor em Geografia, Professor do Programa de Pós-graduação em Gestão dos Recursos Naturais e Desenvolvimento Local na Amazônia (PPGEDAM) do Núcleo de Meio Ambiente (NUMA) da Universidade Federal do Pará (UFPA).
} 


\title{
REVERSE LOGISTICS AND ENVIRONMENTAL LAWS IN BRAZIL
}

\begin{abstract}
This paper aims to demonstrate the relationship between the environmental norms and laws and the reuse of waste and reverse logistic technologies in Brazil. A revision of Brazilian laws, regulations and points of view in environmental management, shows the improvements and perspectives of advanced recycling and reverse logistic technologies enabling companies and enterprises to enhance their recycling capacities and improve their environmental image. We can conclude that reverse logistics can be implemented by various means, but basically requires regulations issued through executive decrees. This is an advantage that must be seized by the business sector, in order to join forces and opportunities to deal with the increasing enormous amounts of waste and the resulting environmental impacts, while achieving positive social and economic results of investments.
\end{abstract}

Keywords: Brazil. Reverse logistics. Environmental Laws. 


\section{ARTIGO}

INOVAÇÃO

\section{INTRODUÇÃO}

No contexto de convenções e tratados ambientais nacionais e internacionais, é de fundamental importância pensar na maneira como as empresas lidam com seus resíduos, evitando a poluição e a degradação do planeta.

Dentro de um Sistema de Gestão Ambiental nas organizações, além dos selos da ISO 14001, pode-se pensar em novas maneiras de aproveitar o desperdício e os resíduos como uma ferramenta para a estratégia de negócios, dentro do conceito de marketing verde, com amplas possibilidades de novas formas de energia limpa, preservando o meio ambiente e melhorando os recursos.

O ambientalismo surge da idéia de preservação e conservação do meio ambiente, mas a sociedade precisa usar os recursos naturais e as empresas precisam de maior eficiência para alcançar resultados econômicos e sociais, considerando a realidade ambiental de hoje. O mercado é insuficiente para regular esses processos e as instituições públicas enfrentam grandes dificuldades para implementar leis e as mudanças necessárias aceitas e acordadas em tratados internacionais.

A preocupação atual é cumprir as normas legais e legitimar as atividades socioambientais, aliadas a ferramentas estratégicas que podem favorecer o crescimento econômico de novos mercados e clientes mais conscientes, o que é um diferencial competitivo (CUNHA, 2008).

A Conferência das Nações Unidas sobre Meio Ambiente e Desenvolvimento Humano que ocorreu na cidade brasileira do Rio de Janeiro teve grande impacto na política nacional. Conhecida mundialmente como RIO-92, foi uma das maiores reuniões de chefes de estado registada no final do Século XX, com a participação de 117 países e uma audiência pública de mais de 22.000 pessoas, através de vários meios de divulgação.

Esta conferência consolidou o conceito de Desenvolvimento Sustentável e proporcionou a assinatura de uma série de acordos, convenções e protocolos, entre os quais a Agenda 21. Essa agenda estabeleceu um compromisso entre as nações signatárias com o objetivo de adotar métodos de proteção ambiental, justiça social e econômica.

Os principais acordos lançados durante a Rio 92 foram:

- A Declaração do Rio que foi o documento mais importante e simbólico da Conferência e, segundo os organizadores, era o equivalente ambiental da Declaração Universal dos Direitos Humanos. 
- O documento da Agenda 21 que tinha 2.500 recomendações, cobrindo várias questões relacionadas à proteção ambiental e desenvolvimento social.

- A Convenção do Clima que produziu um acordo sobre a redução de emissões de gases poluentes nos países signatários.

- A Convenção sobre Biodiversidade que estabeleceu métodos e processos para os países acessarem seus recursos da biodiversidade, fornecendo transferência de tecnologia de pesquisa e reconhecimento de patentes.

- A Declaração de Princípios Florestais que contém um conjunto de 15 princípios relacionados ao manejo e conservação de florestas, sendo o primeiro documento a tratar de questões florestais em nível universal.

Dessa forma a Conferência Rio - 92 foi um marco em questões ambientais promovidas pela ONU e o principal ponto de partida de muitas reuniões e conferências internacionais importantes sobre questões ambientais.

\section{BREVE HISTÓRICO DAS POLÍTICAS AMBIENTAIS NO BRASIL}

Quase dez anos após a Conferência de Estocolmo o governo brasileiro promulgou a Lei Federal no 6.938, em 31 de agosto de 1981, que estabeleceu a Política Nacional do Meio Ambiente (PNMA), e instituiu o Sistema Nacional do Meio Ambiente (SISNAMA), o Conselho Nacional do Meio Ambiente (CONAMA), o licenciamento ambiental e o Registro Técnico de Atividades e Instrumentos de Defesa Ambiental. Instituições e instrumentos básicos para estruturar a gestão ambiental, destaca-se também a institucionalização da responsabilidade com aplicação de sanção para os causadores de danos ambientais.

A PNMA contém princípios, objetivos e instrumentos para uma nova maneira de usar os recursos naturais no Brasil, foi a primeira legislação ambiental federal a lidar sistematicamente com questões ambientais, pautada nos princípios da Convenção de Estocolmo de 1972. Para implementar a PNMA, o SISNAMA serve como um sistema organizacional das entidades da União Federal, Estados, Municípios e do Distrito Federal. O objetivo era implementar a PNMA por meio de um conjunto descentralizado de políticas de gestão ambiental, compartilhando ações entre as entidades administrativas da sociedade.

O Conselho Nacional do Meio Ambiente, bem como os Conselhos Estaduais foram chamados a editar normas, ajustar ações administrativas em questões ambientais, dos conselhos consultivos, normativos e deliberativos para materializar um sistema de governança ambiental, na qual a tomada de decisão ocorre com a representação do Poder Público, da Iniciativa Privada 
e da Sociedade Civil Organizada, inaugurando um novo modelo de tomada de decisão em gestão ambiental.

Entre outras medidas, a PNMA tornou obrigatório o licenciamento e o monitoramento de atividades efetivas ou potencialmente poluidoras, por meio da chamada Avaliação de Impacto Ambiental (AIA), que permite ao Ministério Público promover inquéritos administrativos e ações judiciais sobre responsabilidade civil e criminal por danos ambientais.

\subsection{A CONSTITUIÇÃO BRASILEIRA DE 1988}

Marco histórico no processo de redemocratização do Brasil, a adoção da nova Constituição Brasileira em 1988, conhecida como Constituição Cidadã, forneceu uma sólida base jurídica para questões ambientais. Pela primeira vez na história, uma constituição brasileira dedica um capítulo inteiro a essas questões, garantindo a todos o direito a desfrutar de um ambiente ecologicamente equilibrado (artigo 225, caput). Estabelece as competências ambientais legislativas e administrativas por meio do federalismo cooperativo entre as entidades federadas (artigos 21 a 30). Nesse contexto, destacou-se o papel do município, que se tornou uma entidade federativa, e como entidade estadual mais próxima do cidadão, suas competências foram decorrentes de autonomia administrativa e financeira, incluindo questões ambientais.

A Constituição Federal, dentre outras referencias ambientais, também estabeleceu sanções, criminais e administrativas por danos causados ao meio ambiente por entidades públicas ou privadas, independentemente da obrigação de indenizar os danos causados ao meio ambiente (parágrafo $3^{\circ}$ do artigo 225).

\subsection{O PROGRAMA DE DEFESA DOS ECOSSISTEMAS AMAZÔNICOS COMPLEXOS} DE 1988

Logo após a promulgação da Constituição Federal de 1988, o governo federal editou o Decreto Federal $n^{\circ}$ 96.944, de 12 de outubro de 1988, que inaugura o programa conhecido como "Nossa Natureza" ou "Programa de Defesa dos Ecossistemas Amazônicos Complexos" considerado um marco nas ações em defesa dos recursos naturais na Amazônia brasileira.

O programa foi desenvolvido para regular as condições de uso e preservação dos recursos naturais e ambientes da Amazônia Legal, em um esforço comum para envolver todas as agências governamentais e a sociedade civil. Esse programa posteriormente instituiu a 
criação de várias áreas protegidas na Amazônia, destacando as Florestas Nacionais SaracaTaquera, Carajás e Tapirapé-Aquiri, entre outras.

Para a coordenação geral do programa foi designado o general Rubens Bayma Denis, que deveria estabelecer um grupo de trabalho interministerial para produzir (em 90 dias) um relatório sobre problemas ambientais destacados na Amazônia Legal. Numa triste coincidência, no mesmo período ocorre o assassinato do ecologista e líder dos seringueiros Chico Mendes, fato que chocou o país e teve grande repercussão internacional.

A morte de Chico Mendes e seu impacto na opinião pública, juntamente com outros fatores, levaram o governo federal a criar, por meio da Lei Federal $n^{\circ} 7.735 / 1989$, o Instituto Brasileiro de Meio Ambiente e Recursos Naturais Renováveis (IBAMA), a partir da fusão de vários órgãos que já atuavam na gestão de recursos naturais específicos como da floresta e da pesca. A criação do IBAMA inaugurou uma nova fase da história da gestão ambiental brasileira, considerando que o IBAMA faz parte do SISNAMA como órgão de governança da esfera federal, atualmente divide a função de órgão gestor com o Instituto Chico Mendes de Conservação da Biodiversidade - ICMBio, criado por meio da Lei Federal No 11.516 de 28 de agosto de 2007, com a finalidade de executar ações referentes às atribuições federais da política de unidades de conservação.

\subsection{A LEI DE CRIMES AMBIENTAIS DE 1998}

Assegurada pela nova Constituição brasileira, expressa em seu artigo 225, que reconhece o direito de todos a um meio ambiente saudável, a responsabilidade pela proteção do meio ambiente foi atribuída ao poder público e à sociedade civil. A violação das leis ambientais foi um crime, no entanto, a promulgação desta nova Lei Federal, no 9.605/98, e a aplicação de sanções por danos ambientais foi um grande desafio devido à falta, contradições e conflitos entre leis existentes.

Com a aprovação e aplicação da Lei de Crimes Ambientais, as sanções foram focadas em crimes contra fauna, flora, recursos hídricos e meio ambiente em geral. As sanções administrativas em nível federal podem ser aplicadas, uma vez que estados e municípios têm o poder de legislar sobre sanções administrativas em suas jurisdições territoriais. A Lei de Crimes Ambientais foi um passo importante para proteger a natureza e garantir que a impunidade não seria mais a marca registada dos danos ambientais. 


\subsection{O SANEAMENTO AMBIENTAL}

No plano internacional destaca-se a importância do saneamento básico, como direito fundamental do cidadão a partir da Resolução no 64/92 da ONU em 2010, que reconhece o direito dos cidadãos de ter acesso a sistemas de água e esgoto, como essenciais aos direitos humanos. Atualmente no Brasil a regência da materia é feita pela Política Nacional de Saneamento Básico, instituída pela Lei Federal n 11.445, em 2007. Porém a Lei Federal $n^{\circ}$ 6.766/1979, já tinha estabelecido um conjunto de regras para a urbanização, conhecida como "Lei de Lehmann", no entanto, sem definir uma política nacional para sua implementação.

Por meio da Lei de Lehmann, o Brasil estabeleceu Diretrizes Nacionais para a Política Federal de Saneamento Básico, com base em quatro áreas principais de saneamento: Drenagem, Resíduos Sólidos, Saneamento e Abastecimento de Água.

Com base na definição dessas diretrizes, a Política Federal de Saneamento Básico definiu seus princípios, dando destaque às ações dos municípios, como detentora de serviços de saneamento básico e limpeza pública. Esse papel ganhou maior destaque com a aplicação de outras leis importantes, como Resíduos Sólidos, Consórcios Públicos e a Lei de Parcerias Públicas e Privadas.

\section{A GESTÃO AMBIENTAL NO BRASIL}

O processo de gerenciamento ambiental no Brasil começou nos anos setenta pelos estados da federação como forma de controlar principalmente as atividades poluidoras de zonas industriais e de grandes projetos. Em 1975, o Governo Federal promulgou a Lei no 1.413/75, que visava identificar a poluição ambiental causada por atividades industriais e permitiu ao poder público estabelecer o controle da poluição e contaminação ambiental para a operação de indústrias no país.

Nesse contexto foi aprovada a Lei Federal nº 6.803/1980, que estabeleceu diretrizes para a implantação de indústrias e zoneamento de áreas ambientalmente identificadas como críticas. Essa lei também previa a necessidade de licenciamento ambiental no caso de implantação, operação e expansão de estabelecimentos industriais.

Em 1981, a Política Nacional do Meio Ambiente, por meio de seu regulamento, instituiu procedimentos para o licenciamento ambiental. Estabeleceu a competência originária para os Órgãos Estaduais Ambientais, mas poderia ser assumida pelo Governo Federal, quando os Estados ainda não estavessem estruturados para executar tarefas de gestão ambiental. Essa 


\section{ARTIGO}

INOVAÇÃo

competência também poderia ser delegada aos municípios se eles já estivessem estruturados na área.

Para o exercício da Gestão Ambiental três elementos básicos são necessários: a lei ambiental, o conselho público e um órgão de administração. Atualmente a Lei Complementar Federal n 140/11 regulamentou o disposto na Constituição Federal de 1988 sobre a distribuição de competências administrativas, comuns a todas as entidades federativas (união, estados e municípios).

Por meio dessa lei institui-se a chamada Gestão Ambiental Compartilhada, na qual a dimensão dos impactos ambientais passam a ser definidos como pressupostos e critérios para identificar qual ente federal deve exercer o controle e a fiscalização através do licenciamento e do monitoramento ambiental, aplicando o princípio da prevenção, bem como normas para a cooperação entre as entidades da federação no que se refere à adoção de ações administrativas relacionadas a proteção ao meio ambiente e o combate a poluição em qualquer de suas formas.

\section{A LOGÍSTICA REVERSA E PLANO NACIONAL DE RESÍDUOS SÓLIDOS}

Para fazer cumprir e assegurar a todos o direito a um ambiente ecologicamente equilibrado, como um bem comum usado pelo povo e essencial para uma qualidade de vida saudável, devendo ser defendido e preservado tanto pelo Poder Público como pela comunidade para as gerações presentes e futuras. Conforme o disposto na Constituição Federal, o governo brasileiro editou várias normas legais para implementar ações de política ambiental, dentre elas a Política Nacional de Resíduos Sólidos (PNRS), instituída pela Lei Federal no 12.305, de agosto de 2010.

A Política Nacional de Resíduos Sólidos é uma política ambiental, pois integra a Política Nacional do Meio Ambiente e articula-se com as diretrizes nacionais para o saneamento básico, conforme o estabelecido na Política Federal de Saneamento Básico e com a Política Nacional de Educação Ambiental. Essa norma legal descreve um conjunto de princípios, objetivos, instrumentos, diretrizes, metas e ações que devem ser adotadas pelo Governo Federal, isoladamente ou em cooperação com Estados, Distrito Federal, Municípios ou entidades privadas, a fim de envolver todos esses setores em uma gestão integrada e ambientalmente correta dos resíduos sólidos.

Observa-se que a PNRS reúne em suas diretrizes as normas estabelecidas por outros quatro sistemas importantes, que juntos complementam a Política Nacional de Resíduos Sólidos, a saber: Sistema Nacional do Meio Ambiente - SISNAMA, Sistema Nacional de 
Vigilância Sanitária - SNVS, Sistema Unificado de Atenção à Saúde Agrícola - SUASA e Sistema Nacional de Metrologia, Normalização e Qualidade Industrial - SINMETRO.

Os principais objetivos da implementação da PNRS podem ser resumidos nos seguintes itens: Proteção da saúde pública e ambiental; incentivar a indústria de reciclagem; adoção de logística reversa, acordos setoriais e responsabilidade compartilhada; implantação de planos de resíduos sólidos nos níveis nacional, estadual, metropolitano, intermunicipal, municipal e setorial; fim de lixões abertos e aleatórios e implantação de aterros sanitários e inclusão social.

A PNRS também é uma espécie de alerta para a sociedade, a fim de começar a agir de maneira integrada para alcançar as mudanças necessárias em seu comportamento em relação ao consumo e ao descarte de resíduos. Acima de tudo, destacando a responsabilidade das fontes geradoras de resíduos sólidos e seu destino final adequado, removendo o entendimento anteriormente consolidado de que é de responsabilidade exclusiva do poder público local cuidar do destino de todos os tipos de resíduos. De acordo com o que prevê a PNRS, o Município tem a responsabilidade pela coleta e destinação de resíduos sólidos domésticos classificados como orgânicos ou úmidos.

A PNRS propõe uma mudança de comportamento em relação à gestão de resíduos, que se tornou um dos maiores desafios ambientais globais deste século. Assim, a sociedade deve assumir, como fonte geradora de resídous sólidos, a responsabilidade compartilhada no ciclo de vida dos produtos que consome, desde a extração de recursos naturais, produção e consumo de bens até a destinação final de seus resíduos. Esse esforço conjunto para reduzir o desperdício gerado pela sociedade é essencial para uma melhor qualidade de vida.

Uma das principais inovações trazidas pela PNRS foi a introdução e previsão da Logística Reversa e a responsabilidade compartilhada pelo ciclo de vida dos produtos como instrumentos de política ambiental, que implica em ações orientadas por princípios, em especial o da ecoeficiência "mediante a compatibilização entre o fornecimento, a preços competitivos, de bens e serviços qualificados que satisfaçam as necessidades humanas e tragam qualidade de vida e a redução do impacto ambiental e do consumo de recursos naturais a um nível, no mínimo, equivalente à capacidade de sustentação estimada do planeta" (Brasil, 2010a, art. $6^{\circ}$, V). A PNRS também conceitua sobre o ciclo de vida dos produtos, indicando um conjunto de regras para fabricantes, importadores, distribuidores e comerciantes, consumidores e detentores de serviços públicos de limpeza urbana e gestão de resíduos sólidos, para minimizar o volume de resíduos sólidos e reduzir os impactos causados à saúde humana.

A Logística Reversa tem, portanto, um papel crescente como instrumento de responsabilidade compartilhada e, de acordo com a PNRS, é definida como: “instrumento de 
desenvolvimento econômico e social caracterizado por um conjunto de ações, procedimentos e meios destinados a viabilizar a coleta e a restituição dos resíduos sólidos ao setor empresarial, para reaproveitamento, em seu ciclo ou em outros ciclos produtivos, ou outra destinação final ambientalmente adequada" (Brasil, 2010a, art. $3^{\circ}$, XII).

A PNRS foi regulamentada pelo Decreto Federal no 7.404/2010, a Logística Reversa pode ser implementada e operacionalizada por diversos instrumentos, dentre os quais podemos destacar: a regulamentação emitida pelo Poder Público, os Termos de Compromisso e os acordos setoriais "firmados com menor abrangência geográfica podem ampliar, mas não abrandar, as medidas de proteção ambiental constantes dos acordos setoriais e termos de compromisso firmados com maior abrangência geográfica” (Brasil, 2010, art. 15).

Outro instrumento de grande importância é o Sistema Nacional de Informações sobre a Gestão dos Resíduos Sólidos (SINIR) o qual é o principal instrumento de informações e dados contemplando o Sistema Nacional de Informações sobre Meio Ambiente (SINIMA) e o Sistema Nacional de Informações Sobre Saneamento Básico (SINISA), atual SNIS, coordenado pelo Ministério do Desenvolvimento Regional (MDR). O Ministério do Meio Ambiente publicou a Portaria $\mathrm{n}^{\circ}$ 394, de 17 de outubro de 2018, aprovando o Regimento Interno do Comitê Orientador para a Implementação de Sistemas de Logística Reversa. O SINIR é um sistema que contempla praticamente todas as formas de resíduos é pode ser acessado junto ao endereço eletrônico: https://sinir.gov.br/.

\subsection{LOGÍSTICA REVERSA E OS RESÍDUOS DA MINERAÇÃO}

A atividade mineradora no Brasil é regulada pelo Código de Mineração, que dispõe expressamente a respeito do dever do minerador de responder pelos danos resultados direta ou indiretamente da lavra, ademais do dever de evitar a poluição (Brasil, 1967, art. 47, incisos VIII e XI). A destinação final ambientalmente adequada dos resíduos da mineração também estão contemplados pela PNRS, instituída pela Lei n. 12.305/2010, que conceitua como gerador de resíduo sólido a pessoa física ou jurídica que gera resíduos sólidos por meio de suas atividades, e exige a sua reutilização, visando minimizar os impactos ambientais adversos, através da denominada logística reversa, que consiste no reaproveitamento do resíduo em seu próprio ciclo ou em outro ciclo produtivo (Brasil, 2010a, art. $3^{\circ}$, incisos VII e IX).

O maior dano ambiental já registrado na história dos rompimentos de barragens ocorreu com o rompimento da barragem de rejeitos de Fundão, em Mariana-MG, no dia 05 de novembro de 2015, e que o mais recente desastre na Barragem I, da Mina Córrego do Feijão, em 
Brumadinho-MG, ocorrido em 25 de janeiro de 2019, ainda em apuração, tende a se transformar na pior tragédia humana provocada por rompimento de barragens de minério das últimas três décadas.Conforme os relatórios da Defesa Civil do Estado de Minas Gerais, até o mês de Dezembro de 2019, 254 (duzentos e cinquenta e quatro) corpos já haviam sido identificados e pelo menos 16 (dezesseis) ainda estão desaparecidos.

O custo social (externo) da poluição do meio ambiente deve ser internalizado pelo poluidor, ou seja, deve ser levado em conta quando da mensuração dos custos de produção e consequentemente assumido pelo empreendedor (internalização dos custos externos). Como regra a mineração é atividade altamente poluidora e lucrativa ao mesmo tempo, devendo a internalização de custos ser realizada por meio da imposição ao minerador da adoção de todas as tecnologias conhecidas e viáveis para a redução dos danos ambientais oriundos da atividade por meio da logística reversa.

O Decreto Federal n 9.406, de 12 de junho de 2018, que regulamentou o Código de Mineração dispões expressamente em seu artigo 10, parágrafos $2^{\circ}$ e $3^{\circ}$, que o Ministério de Minas e Energia e a Agência Nacional de Mineração estimularão os empreendimentos destinados a aproveitar rejeito, estéril e resíduos da mineração, inclusive mediante aditamento ao título por meio de procedimento simplificado. Ficando a cargo da Agência Nacional de Mineração regulamentar o aproveitamento do rejeito, do estéril e dos resíduos da mineração, ou seja, a logística reversa dos rejeitos de mineração.

A Agência Nacional de Mineração assim o fez por meio da recente Resolução $N^{\circ} 13$, de 8 de agosto de 2019, restando contemplado expressamente no artigo $2^{\circ}$ a proibição da utilização do método de alteamento de barragens de mineração denominado "a montante" em todo o território nacional. No qual, em síntese parte dos resíduos da própria atividade mineradora são utilizados para a construção das barragens. Inicialmente o alteamento das barragens com a utilização dos próprios rejeitos da mineração é uma solução compatível com a logística reversa. No entanto, em razão dos graves acidentes mencionados acima estão proibidos.

Com relação ao rompimento da barragem em Mariana MG, em 2015, a Fundação Renova, responsável pela reparação dos danos da tragédia, encomendou um Estudo de Avaliação de Risco à Saúde Humana (ARSH), realizado pela empresa Ambios Engenharia e Processos $^{6}$. Uma das soluções encontradas foi a utilização dos próprios rejeitos para fins de aterramentos e construções de ruas e pavimentação. Ocorre que o relatório mencionado no

\footnotetext{
${ }^{6}$ Denominado "ESTUDO DE AVALIAÇÃO DE RISCO À SAÚDE HUMANA EM LOCALIDADES ATINGIDAS PELO ROMPIMENTO DA BARRAGEM DO FUNDÃO-MG”. (acesso em novembro de 2019 https://apublica.org/wp-content/uploads/2019/11/ambios-arsh-mariana-e-barra-linga-final-20190417.pdf,).
} 


\section{ARTIGO}

INOVAÇÃo

parágrafo anterior trouxe a contaminação dos moradores das comunidades com metais pesados presentes nos rejeitos, principalmente pelo ar. Supostamente a poeira dos resíduos possuem elementos tóxicos que estão causando graves problemas de saúde na população. Assim, a legislação ambiental brasileira contempla de forma expressa a logística reversa nos resíduos da mineração, mas ainda existem muitos desafios a serem superados.

\subsection{LOGÍSTICA REVERSA E OS AGROTÓXICOS}

A destinação inadequada de embalagens de agrotóxicos e afins, vazias ou contendo resíduos, causam danos ao meio ambiente e à saúde humana e a previsão expressa na Lei ${ }^{\circ}$ 12.305 de 2010, que instituiu a Política Nacional de Resíduos Sólidos, em seus arts. 30 e 33, instituiu a responsabilidade compartilhada pelos resíduos de produtos agrotóxicos, obrigando o consumidor a devolver as embalagens contendo resíduos, além das embalagens vazias.

A logistica reversa dos resíduos e embalagens de agrotóxicos restam amplamente contemplados no ordenamento jurídicos brasileiro, em especial pela Lei $n^{\circ} 7.802$, de 11 de julho de 1989 e pelo Decreto Federal n ${ }^{\circ}$ 4.074, de 04 de janeiro de 2002, ambos instrumentos normativos trazem a obrigatoriedade tanto para as empresas produtoras de agrotóxicos e também para os usuários pessoas físicas e jurídicas a correta destinação final de sobras e embalagens.

Destacamos que os artigos 51 a 60 do Decreto $n^{\circ} 4.074 / 2002$, dispoem sobre a possibilidade da empresa produtora de agrotóxicos reutilizar as embalagens. Da mesma forma os usuários de agrotóxicos e afins deverão efetuar a devolução das embalagens vazias, e respectivas tampas, aos estabelecimentos comerciais em que foram adquiridos, observadas as instruções constantes dos rótulos e das bulas, no prazo de até um ano, contado da data de sua compra.

No caso de embalagens contendo produtos impróprios para utilização ou em desuso, o usuário observará as orientações contidas nas respectivas bulas, cabendo às empresas titulares do registro, produtoras e comercializadoras, promover o recolhimento e a destinação admitidos pelo órgão ambiental competente. $\mathrm{E}$ ainda que as embalagens rígidas, que contiverem formulações miscíveis ou dispersíveis em água, deverão ser submetidas pelo usuário à operação de tríplice lavagem, ou tecnologia equivalente, conforme orientação constante de seus rótulos, bulas ou folheto complementar.

As empresas titulares de registro, produtoras e comercializadoras de agrotóxicos, seus componentes e afins, são responsáveis pelo recolhimento, pelo transporte e pela destinação final 
das embalagens vazias, devolvidas pelos usuários aos estabelecimentos comerciais ou aos postos de recebimento, bem como dos produtos por elas fabricados e comercializados. Quando o produto não for fabricado no País, a pessoa física ou jurídica responsável pela importação assumirá, com vistas à reutilização, reciclagem ou inutilização, a responsabilidade pela destinação.

A Resolução CONAMA nº 465, de 05 de dezembro de 2014, regulamentou os requisitos e critérios técnicos mínimos necessários para o licenciamento ambiental de estabelecimentos destinados ao recebimento de embalagens de agrotóxicos e afins, vazias ou contendo resíduos, trazendo expressamente a responsabilidade de cada participante do sistema de logística reversa de embalagens de agrotóxicos, dentro das responsabilidades compartilhadas.

Tais dispositivos normativos de fato precisam ser efetivados e colocados em prática, uma vez que apenas no ano de 2019 o Ministério da Agricultura oficializou 474 (quatrocentos e setenta e quatro) novos agrotóxicos, agora denominados por defensivos agrícolas. Os novos produtos têm a autorização por meio de atos do Departamento de Sanidade Vegetal e Insumos Agrícolas da Secretaria de Defesa Agropecuária, dentre os quais destaca-se o ATO nº 42, de 19 de junho de 2019, com o registro de 42 defensivos agrícolas. Desse total, apenas um produto traz um ingrediente ativo novo, os demais são produtos genéricos que já estavam presentes em outros produtos existentes no mercado.

A grande justificativa para a liberação dos defensivos agrícolas genéricos é reduzir os custos. No entanto, seria de grande importância o desenvolvimento concomitante das políticas públicas da logística reversa para a correta destinação final de sobras e embalagens na mesma proporção em que os agrotóxicos são autorizados.

\section{CONSIDERAÇÕES FINAIS}

É possível observar que a Logística Reversa pode ser implementada por vários meios, mas principalmente por regulamentos emitidos por decretos executivos. Isso deve ser aproveitado pelo setor empresarial, a fim de unir forças e oportunidades para lidar com o meio ambiente de maneira responsável e, ao mesmo tempo, obter resultados sociais e econômicos para quem investe.

O Brasil já possui leis importantes em defesa do meio ambiente, mas estas precisam ser aplicadas de forma sistemática e estruturada. No caso da Logística Reversa, é necessário um comitê composto por técnicos de cinco ministérios (Meio Ambiente, Desenvolvimento, Indústria e Comércio, Pecuária e Abastecimento, Agricultura e Saúde) para verificar a 


\section{ARTIGO}

INOVAÇÃO

viabilidade técnica e econômica da proposta. Além disso, antes de sua implementação, os sistemas de Logística Reversa devem ser submetidos a consulta pública. Isso precisa ser resolvido para transformar os desafios e os problemas em oportunidades para os investidores.

Para implementar um sistema de Logística Reversa, recomenda-se também a realização de Acordos Setoriais entre os setores público e privado para sua implementação e operacionalização. Tais acordos são contratos simples estabelecidos entre a autoridade pública e a cadeia de produção e distribuição de certos tipos de produtos, a fim de garantir a responsabilidade compartilhada efetiva ao longo do ciclo de vida dos produtos comercializados.

Em outras situações, se não houver acordo setorial ou regulamentação específica estabelecida pelo Decreto Federal n ${ }^{\circ} 7404 / 2010$, ou em situações que exijam o estabelecimento de compromissos e metas complementares, o poder público poderá assinar Termos de Compromisso - TC - com os fabricantes, distribuidores e comerciantes de produtos da Logística Reversa. No entanto, esses Termos de Compromisso somente serão efetivos após sua homologação oficial, feita por órgãos ambientais reconhecidos e membros do Sistema Nacional de Meio Ambiente - SISNAMA.

Por fim, parece certo que os instrumentos legais necessários para a implementação da Logística Reversa no Brasil já estão em vigor, mas ainda precisam de maior aderência à sua proposta, o que certamente aumentará o desenvolvimento social e econômico com base em princípios ecológicos mais sustentáveis. 


\section{REFERÊNCIAS}

BRASIL. [Constituição (1988)]. Constituição da República Federativa do Brasil. Promulgada em 5 de outubro de 1988. Brasília, 1988a.

BRASIL. Ato $\mathrm{n}^{\circ}$ 42, de 19 de junho de 2019. Registros de Agrotóxicos. Diário Oficial da União: seção 1: Ministério da Agricultura, Pecuária e Abastecimento/Secretaria de Defesa Agropecuária/Departamento de Sanidade Vegetal e Insumos Agrícolas/Coordenação-Geral de Agrotóxicos e Afins, p. 4, jun. 2019a.

BRASIL. Decreto Federal no 4.074, de 04 de janeiro de 2002. Regulamenta o Controle, a Inspeção e a Fiscalização de agrotóxicos, seus componentes e afins. Diário Oficial da União: seção 1, p. 1, jan. 2002.

BRASIL. Decreto Federal n 7.404 de 23 de dezembro de 2010. Regulamenta a Lei no 12.305, de 2 de agosto de 2010, que institui a Política Nacional de Resíduos Sólidos, cria o Comitê Interministerial da Política Nacional de Resíduos Sólidos. Diário Oficial da União: seção 1, Brasília, DF, dez. 2010b.

BRASIL. Decreto Federal n ${ }^{\circ}$ 9.406, de 12 de junho de 2018. Regulamenta o Decreto-Lei ${ }^{\circ}$ 227, de 28 de fevereiro de 1967, a Lei $\mathrm{n}^{\circ}$ 6.567, de 24 de setembro de 1978, a Lei $\mathrm{n}^{\circ}$ 7.805, de 18 de julho de 1989, e a Lei no 13.575, de 26 de dezembro de 2017. Diário Oficial da União: seção 1. Brasília, DF, p. 1, jun. 2018 b.

BRASIL. Decreto Federal no 96.944 de 12 de outubro de 1988. Institui o Programa de Defesa do Complexo de Ecossistemas da Amazônia Legal. Diário Oficial da União: seção 1, Brasília, DF, out. 1988b.

BRASIL. Decreto Lei no 1.413 de 14 de agosto de 1975. Dispõe sobre o controle da poluição do meio ambiente provocada por atividades industriais. Diário Oficial da União: seção 1, Brasília, DF, ago. 1975.

BRASIL. Decreto-Lei n. ${ }^{\circ}$ 227, de 28 de Fevereiro de 1967. Código de Mineração. Diário Oficial da União: seção 1, Brasília, DF, p.2417, fev. 1967.

BRASIL. Lei Complementar $n^{\circ} 140$ de 8 de dezembro de 2011. Fixa normas, nos termos dos incisos III, VI e VII do caput e do parágrafo único do art. 23 da Constituição Federal, para a cooperação entre a União, os Estados, o Distrito Federal e os Municípios. Diário Oficial da União: seção 1, Brasília, DF, dez. 2011.

BRASIL. Lei Federal no 11.445 de 5 de janeiro de 2007. Política Nacional de Saneamento Básico. Diário Oficial da União: seção 1, Brasília, DF, p. 3, jan. 2007.

BRASIL. Lei Federal n ${ }^{\circ} 12.305$ de 2 de agosto de 2010. Política Nacional de Resíduos Sólidos. Diário Oficial da União: seção 1, Brasília, DF, p. 3, ago. 2010a.

BRASIL. Lei federal n 12.651 de 25 de maio de 2012. Código Florestal Brasileiro. Diário Oficial da União: seção 1, Brasília, DF, p. 1, maio 2012. 
BRASIL. Lei Federal no 6766 de 19 de dezembro de 1979. Dispõe sobre o Parcelamento do Solo Urbano e dá outras Providências. Diário Oficial da União: seção 1, Brasília, DF, p. 19457, dez.1979.

BRASIL. Lei Federal nº 6803 de 2 de julho de 1980. Dispõe sobre as diretrizes básicas para o zoneamento industrial nas áreas críticas de poluição, e dá outras providências. Diário Oficial da União: seção 1, Brasília, DF, p. 13210, jul. 1980.

BRASIL. Lei Federal no 6938 de 31 de agosto de 1981. Institui o Sistema Nacional de Meio Ambiente. Diário Oficial da União: seção 1, Brasília, DF, set. 1981.

BRASIL. Lei Federal no 7.735 de 22 de fevereiro de 1989. Cria o Instituto Brasileiro do Meio Ambiente e dos Recursos Naturais Renováveis. Diário Oficial da União: seção1, Brasília, DF, p. 2729, fev. 1989a.

BRASIL. Lei Federal n n $^{\circ} .605$ de 12 de fevereiro de 1988. Dispõe sobre as sanções penais e administrativas derivadas de condutas e atividades lesivas ao meio ambiente. Brasilia: Diário Oficial da União, fev. 1988.

BRASIL. Lei n ${ }^{\circ}$ 7.802, de 11 de julho de 1989. Lei dos Agrotóxicos. Dispõe sobre a pesquisa, a experimentação, a produção, a embalagem e rotulagem, o transporte, o armazenamento, a comercialização, a propaganda comercial, a utilização, a importação, a exportação, destino final dos resíduos e embalagens, o registro, a classificação, o controle, a inspeção e a fiscalização de agrotóxicos, seus componentes e afins, e dá outras providências. Diário Oficial da União: seção 1, p. 11459, jul. 1989b.

BRASIL. Portaria no 394, de 17 de outubro de 2018. Aprova o Regimento Interno do Comitê Orientador para a Implementação de Sistemas de Logística Reversa (SINIR). Diário Oficial da União: seção 1: Ministério do Meio Ambiente, Brasília, DF, p. 51, out. 2018a.

BRASIL. Resolução CONAMA no 465, de 05 de dezembro de 2014. Requisitos e critérios técnicos mínimos necessários para o licenciamento ambiental de estabelecimentos destinados ao recebimento de embalagens de agrotóxicos e afins, vazias ou contendo resíduos. Diário Oficial da União: seção 1, p. 110-111, dez. 2014.

BRASIL. Resolução No 13, de 8 de agosto de 2019. Estabelece medidas regulatórias objetivando assegurar a estabilidade de barragens de mineração, notadamente aquelas construídas ou alteadas pelo método denominado "a montante" ou por método declarado como desconhecido e dá outras providências. Diário Oficial da União: seção 1, p. 44, ago. $2019 b$.

COMISSÃO MUNDIAL SOBRE MEIO AMBIENTE E DESENVOLVIMENTO. Nosso Futuro Comum. 2a . ed. Rio de Janeiro: Fundação Getúlio Vargas, 1991.

CUNHA, J. Adaptação Estratégica e Gestão Ambiental: um estudo das mudanças organizacionais em uma industria de fundição. Biguaçu: Universidade Vale do Itajaí, 2008.

FUNDAÇÃO RENOVA. "Estudo de assessment of human health risk in locations achieved by the breaking of the fundão-mg dam". 2019. Disponível em:

https://www.fundacaorenova.org/wpcontent/uploads/2016/10/ambiosarshmarianaebarralongaf inal20190417.pdf. Acesso em: fevereiro de 2020. 
GONÇALVES, C. W. P. Os (des)caminhos do meio ambiente. São Paulo: Contexto, 2006.

GUERRA, F. X. A Nação Moderna: nova legitimidade e velhas identidades. In: JANCSÓ, Istvan (org.) Brasil: formação do Estado e da Nação. São Paulo: Hucitec / Fapesp, 2002.

LEMOS, Patrícia Faga Iglecias. Resíduos Sólidos e a Responsabilidade Civil Pós-

Consumo. Editora Revista dos Tribunais. São Paulo. 2014.

MACHADO, P. A. L. Estudos de Direito Ambiental. São Paulo: Malheiros, 1994.

PARÁ (PA). Decreto estadual n ${ }^{\circ} 2593$ de 27 de novembro de 2006. Institui o Lincenciamento Ambiental Rural - LAR. Diário Oficial do Estado do Pará, nov. 2006.

ROCHA, C. R.; COELHO, M. C. Direito Ambiental e Desenvolvimento Sustentável: o patrimônio natural explorável em face à priorização de paisagens autênticas. Site Publicadireito, 2012. Disponivel em:

<http://www.publicadireito.com.br/artigos/?cod=9b698eb3105bd825>. Acesso em: 17 maio 2017.

RUIVO, M. Balanço e Perspectiva da Eco 92 - Do Crescimento Zero a um Desenvolvimento Sustentável. In: COTRIM, João Paulo (Coord). De Planeta na Mãos: No Pós Eco 92. Lisboa: Colibri, 1993. 